\title{
Konsep I'rab Dalam Pandangan Ibrahim Musthafa dan Ibrahim Anis
}

\author{
Hazuar \\ Institut Agama Islam Negeri Curup \\ Email: azazwae@gmail.com
}

\begin{abstract}
There are some objectives on discussion of I'rab concept in Ibrahim Mustafa and Ibrahim Anis perspectives. The mehod used in this research was Descriptive Analysis. In his book, Ibya' al-Nabwi Ibrahim Mustafa explains that there are only two I'rab; Dhammah and Kasrah. Dhammah functions as subject (Isnad), meanwhile Kasrah functions as majmu' (idhafah). He rejected fathah as i'rab because it is only lines which is seldom communicated by Arabians, and it doesnt infuence meaning for communication. On the contrary, i'rab concept as stated by Ibrahim Anis who declined that there were funtions of i'rab neither rules nor meaning. The findings of this reserch that irab concept stated by Ibrahim Mustafa and Ibrahim Anis was contrast. I'rab concept used by Ibrahim is simillar to Ibnu Mada' al-Qurtubi on which the changing of i'rab was caused of 'amil (actor) as it was used by experts of Nahwu traditionally. However, i'rab concept used by Ibrahim Anis rather the same as the thoughts of Nahwu Qutrub which is extremely used irab in ditermining a meaning. Then Ibrahim Anis view that the function of i'rab was result the experts of Nahwu.
\end{abstract}

Keywords: I'rab concept, Ibrahim Musthafa, Ibrahim Anis

\begin{abstract}
Abstrak
Adapun tujuan pembahasan ini untuk mengulas Konsep i'rab dalam pandangan Ibrahim Musthafa dan Ibrahim Anis. Metode yang digunakan dalam penelitian ini adalah metode Deskriptif Analisis. Dalam karyanya Ihya' al-Nahwi Ibrahim Musthafa menjelaskan bahwa tanda i'rab itu hanya dua; dhammah dan kasrah. Dhammah berfungsi sebagai penanda bawa kata yang ditandai berkedudukan sebagai subjek (isnad), sedangkan kasrab sebagai penanda bahwa kata yang dimaksud berkedudukan sebagai kata majmu' (idhafah). Ia menolak fathah sebagai tanda i'rab, menurutnya fathah hanyalah baris yang dianggap ringan oleh orang Arab dalam komunikasi dan tidak
\end{abstract}


memiliki pengaruh apa-apa dalam menentukan makna. Sementara konsep i'rab yang dikemukan Ibrahim Anis menafikan sama sekali fungsi i'rab, dalam pandangannya tanda i'rab tidak memiliki peran apapun dalam menentukan makna kata. Melalui studi ini dapat di jelaskan bahwa konsep i'rab dalam pandangan Ibrahim Musthafa dan Ibrahim Anis memiliki corak yang bertolak belakang, Kosep i'rab yang dibangun oleh Ibrahim Musthafa lebih condong pada pemikiran Ibnu Mada' al-Qurthubi yang berpandangan bahwa perubahan i'rab bukanlah disebabkan oleh 'amil (aktor) seperti yang dianut para ahli Nahwu Tradisional. Sementara konsep i'rab yang dikemukan Ibrahim Anis memiliki keserupaan dengan pemikiran ulama Nahwu Tradisional Qutrub yang secara ekstrim menafikan fungsi i'rab dalam menentukan sebuah makna, dan dalam pandangan Ibrahim Anis fungsi i'rab dalam itu hanya hasil kreasi para ahli Nahwu.

Kata Kunci: konsep i'rab, Ibrahim Musthafa, Ibrahim Anis.

\section{Pendahuluan}

Bangsa Arab pada masa pra Islam, dikenal sebagai bangsa yang memiliki cita rasa dan perhatian yang tinggi terhadap bahasa. Bagi mereka bahasa bukan hanya sebagai sarana komunikasi semata, lebih dari itu bahasa menjadi senjata yang ampuh untuk meningkatkan status sosial dimata suku-suku yang hidup di jazirah Arab ketika itu. ${ }^{1}$ Para penyair dan orator yang fasib menempati kelas sosial yang istimewa dan tinggi di tengah-tengah masyarakat,pada masanya mereka bagaikan seleberitis yang kehadiran dan penampilannya ditunggu dan dinanti-nantikan. Lalu bermunculan beberapa tempat yang menjadi pusat bagi para penyair atau pujangga untuk membacakan karya-karya mereka seperti pasar 'Ukaz, Drul Majaz dan beberapa tempat lainnya.

Salah satu karakteristik bahasa Arab yang sangat menjadi perhatian dan dijaga oleh bangsa Arab ketika berkomunikasi adalah i'rab. ${ }^{2}$ I'rab adalah istilah yang mengacu pada perubahan bentuk akhir kata, baik perubahan harakat (baris) atau perubahan harf (huruf akhir). ${ }^{3}$ Irab menjadi salah satu standar tolak ukur bagi bangsa Arab untuk menilai fasih tidaknya seseorang dalam berbahasa, adalah sebuah aib bila terdengar sesorang berkomunikasi lalu tidak fasib (labn) dalam komunikasinya. ${ }^{4}$ Sejatinya i'rab bagi bangsa Arab berfungsi menjadi penanda atau

${ }^{1}$ Al-Masluth, Abd al-hamid. Al-Adab Al-Arabi Baina Al-Jabiliyyah wa Al-Islam (Mesir: Al-Mathba'ah al-Muniriyah,1995) hlm, 59

${ }^{2}$ D.Hidayat, Al-Balaghah li Al-Jami' wa al-Syawabid min Kalam al-Badi' (Jakarta: PT. Karya Toha Putra), hlm, 47

3 Abdullah bin Ahmad Al-Fakihi, Syarah al-Fawakih al-Janiyab 'ala Mutammimah alJurumiyah (Bandung: Syirkah al-Ma'arif. t.t), hlm, 7

${ }^{4}$ Musthafa, Ibrahim, Ibya'Al-Nabwi ( Kairo, 1992), cet.2, hlm.9 
tanda bahasa yang mengarah pada fungsi tertentu, dan kemampuan ini mereka peroleh secara alamiah.

Para sejarawan mencatat bahwa praktek berbahasa yang tidak fasib (labn) itu bibitnya telah ada pada masa Rasulullah. ${ }^{5}$ Bahkan pada masa jabiliah fenomena itu sudah ditemukan, hanya saja terbatas pada beberapa gelintir orang. ${ }^{6}$ Ketika bangsa Arab yang telah memeluk Islam berhasil menguasai beberapa wilayah jajahan Romawi dan Persia, terjadilah proses asimilasi budaya yang tidak dapat dielakkan dengan penduduk setempat. Bangsa Arab Muslim yang datang kewilayah baru tidaklah datang sebagai penjajah, mereka datang sebagai pembebas dan pembawa perubahan. Sikap ramah dan humanis yang ditunjukkan para penakluk Muslim Arab ini, menjadi daya tarik tersendiri bagi bangsa taklukan untuk secara sukarela memeluk Islam. ${ }^{7}$

Bangsa-bangsa Muslim non Arab ('ajam) yang baru memeluk Islam sangat bersemangat untuk mempelajari Islam dari sumberya yang asli yaitu alQuran dan Hadis. Motivasi ini tentu menghadapkan mereka pada keharusan mempelajari bahasa Arab. Merupakan sebuah problem bagi sebuah bangsa yang telah memiliki bahasa ibu tersendiri ketika mempelajari bahasa Arab, problem yang muncul di antaranya adalah kesalahan dalam mefungsikan tanda i'rab, kesalahan itu terjadi karena praktek bahasa yang mereka lakukan tidaklah didapat secara alamiah. Terdapat beberapa riwayat yang menyebutan beberapa bentuk kesalahan dalam mefungsikan tanda i'rab dalam komunikasi bahas Arab, bahkan beberapa riwayat menjelaskan bahwakesalahan itu juga terjadi pada bacaan alQuran.8

Banyaknya terjadi kesalahan dalam praktek berbahasa (labn) menjadi kekhawatiran tersendiri bagi banyak tokoh dan kalangan. Kekhawatiran itu semakin bertambah ketika disadari bahwa kesalahan dalam berbahasa itu juga terjadi ketika membaca kitab suci al-Quran. Fenomena yang mengkhawatirkan ini memunculkan inisiatif beberapa tokoh untuk menemukan solusi mengatasi persoalan tersebut. Tercatatlah tokoh bernama Abu al-Aswad al-Duali yang mempelopori usaha mengatasi problem kesalahan dalam praktek berbahasa ini. Riwayat menyebutkan bahwa usaha yang dilakukan Abu al-Aswad al-Duali adalah tindak lanjut instruksi Khalifah Ali bin Abi Thalib. Salah satu jasa besar Abu al-Aswad al-Duali adalah membuat simbol tanda baca atau apa yang kita kenal pada hari ini dengan harakat (baris). Pada mulanya tanda baca itu hanyalah

\footnotetext{
${ }^{5}$ Dhoif, Syauqy. Al-Madaris al-Nabwiyah (Mesir: Daar al-Ma’arif, 1976), hlm. 11

${ }^{6}$ Wahbah, Majdi dan Kamil Al-Muhandis. Mu'jam al-Musthalahat al-Arabiyah fi al-Lughab wa al-Adab (Beirut: Maktabah Lubnan, 1984), hlm. 216

${ }^{7}$ Tamam Hasan, Al-Ushul (Maroko: Dar al-Tsaqofah, 1991), hlm. 27

8 Thanthawi, Muhammad, Nasyatu al-Nabwi wa Tarikbu Asyburi al-Nubat (Kairo: Dar alMa'arif, t.t), cet, 2, hlm. 16-18
} 
berbentuk titik-titik, lalu seiring waktu mengalami beberapa perbaikan dan penyempurnaan sehingga terciptalah tanda baca yang kita kenal saat ini. ${ }^{9}$

Upaya Abu al-Aswad al-Duali dalam mengkaji bahasa Arab, bisa disebut sebagai tonggak rintisan bagi generasi berikutnya untuk lebih dalam lagi mengeksplorasi kajian bahasa Arab. Muncullah setelah itu beberapa tokoh bahasa seperti: Ibn Abi Ishaq, 'Isa ibn Umar al-Tsaqafi, Abu Amar ibn Ala' dan Yunus ibn Habib. Tokoh-tokoh tersebut adalah para ahli bahasa yang mempelopori kajian nabwu (sintaksis Arab). Dalam perjalanannya terbentuklah apa yang dinamakan madrasah atau aliran dalam kajian ilmu Nabwu. Madrasab yang pertama kali berdiri ketika itu adalah madrasab Basrah, nisbat kepada salah satu kota besar di Irak. Muncul setelah itu menyusul beberapa madrasah seperti: Kufah, Baghdad, Andalusia dan Mesir. Tak jauh berbeda degan madzhab Fiqih, madzhab Nahwu memiliki perbedaan-perbedaan dalam menyikapi beberapa isu dalam kajian ilmu Nabwu. ${ }^{10}$

Basrah sebagai Madrasah Nahwu yang pertama berdiri, dikenal jauh sebelum kedatangan islam sebagai pusat budaya dan peradaban yang telah maju. Di kota ini filsafat cukup diminati dan dikaji secara intens. ${ }^{11}$ Ketika agama Nasrani berkembang dan secara politis banyak menguasai wilayah, banyak para filosof yang menyingkir dari pusat-pusat budaya, ini disebabkan sikap tidak simpati penganut Kristen terhadap kajian filsafat yang mereka anggap bid'ah peninggalan kaum Pagan. Ketika di wilayah lain filsafat banyak mendapat tantangan, kota Basrah memberikan iklim yang cukup sejuk bagi perkembangan filsafat. Disaat bangsa Arab muslim tiba di wilayah Irak -secara khusus di kota Basrah- mereka menemukan suatu masyarakat yang telah maju secara budaya dan ilmu pengetahuan.

Berbanding terbalik dengan sikap pemeluk Nasrani terhadap kajian filsafat, bangsa Arab muslim memiliki sikap yang cukup akomodatif dan terbuka terhadap kajian filsafat. Ketika mereka bersemangat mengkaji al-Quran dan Hadis, disaat bersamaan mereka juga mempelajari ilmu-ilmu lain termasuk didalamnya filsafat. Seperti telah disinggung sebelumnya, ketika terjadi banyak terjadi kesalahan dalam praktek bahasa dikalangan orang-orang non Arab ('ajam), muncullah beberapa tokoh yang mencoba membuat terobosan mengatasi problematika tersebut. Abu al-Aswad al-Duali adalah di antara contoh tokoh yang melakukan beberapa upaya tersebut. Sepeninggalnya kajian kebahasaan semakin berkembang dan cakupan kajiannya semakin kaya.

\footnotetext{
${ }^{9}$ Ibid., hlm. 27-28

${ }^{10}$ Asrina, Khilafiyah Nahwriyab: Dialektika Pemikiran Nahwu Basrah dan Kufah dalam Catatan Ibn al-Anbari, MIQOT, vol. XL no. 2 Juli-Desember 2016, hlm. 413-414

${ }^{11}$ Toni Pransiska, Konsep I'rab Dalam Ilmu Nahwu (Sebuab Kajian Epistemologis), al-Mahāra, Vol. 1, No.1, Desember 2015, hlm. 70
} 
Ketika kota Basrah mengambil alih posisi sebagai pusat kajian bahasa, maka muncul banyak tokoh-tokoh yang berpatisipasi dalam menghasilkan karya. Para ahli bahasa Arab yang telah mempelajari ilmu logika dan fisafat, mencoba mengurai problematika kebahasaan yang ada dengan pendekatan filsafat. ${ }^{12}$ Melalui pendekatan ini lahirlah kaidah-kaidah kebahasaan yang kaya dan beragam, sejak saat itu bahasa Arab yang mulanya merupakan bahasa yang memilikitata bahasa sederhana, menjelma menjadi bahasa yang memiliki tata bahasa yang canggih dan mengagumkan. Pendekatan filsafat yang digunakan oleh para ahli bahasa, disatu sisi sangat membantu mengurai persoaalan kebahasaan, disisi lain memunculkan persoalan dan kritik dari beberapa kalangan. kelompok ini melihat bahwa pendekatan filsafat berakibat pada pengabaian terhadap banyak hal penting berkaitan dengan bahasa, terutama mengabaikan fungsi bahasa sebagai sarana komunikasi, sebab pendekatan ini hanya menekankan satu aspek dari bahasa, yaitu: qawaid.

Kajian bahasa yang menjadi sentral kekaguman para ahli dalam mengkaji bahasa Arab adalah ketika mereka berhadapan pada kajian i'rab. Pada mulanya mereka bertanya-tanya mengapa perubahan-perubahan i'rab itu terjadi? Pertanyaan-pertanyaan itu membawa mereka pada satu usaha untuk menemukan jawaban-jawaban atas pertanyaan tersebut. Para ahli bahasa yang telah terpengaruh kajian logika dan filsafat, berpandangan perubahan i'rab yang terdapat dalam bahasa Arab bukanlah suatu yang kebetulan. Ada aktor-aktor tertentu yang mengakibatkan perubahan itu terjadi, belakangan mereka menyebut aktor itu dengan istilah 'amil. Teori 'amil yang mereka munculkan ini jelas satu teori yang terpengaruh dengan kajian filsafat, menurut para ahli filsafat setiap apa yang terjadi didunia ini tidak lepas dari hukum sebab akibat. Berangkat dari teori 'amil ini maka para ahli bahasa berupaya menyusun tata bahasa Arab yang hanya berfokus pada upaya mengungkap 'amil (aktor) yang menjadi penyebab perubahan i'rab. ${ }^{13}$

Pada akhirnya, kajian Nabwu bisa dikatakan hanya berkutat pada bahasan i'rab dan upaya menemukan 'mil yang menjadi aktor perubahan i'rab tersebut. Melihat fenomena ini, belakangan muncul keprihatinan dari beberapa tokoh, di antara mereka itu adalah dua tokoh ahli bahasa Arab kotemporer berkebangsaan Mesir bernama Ibrahim Musthafa dan Ibrahim Anis, Ia merupakan salah seorang anggota Majma' (lembaga) bahasa Arab di Mesir. Ibrahim Musthafa melihat, pendekatan falsafati yang digunakan para ahli bahasa Qudami (tradisional) dalam mendiagnosa fenomena-fenomena kebahasaan tidaklah selalu tepat dan sesuai. Fenomena bahasa itu bersifat lebih sering bersifat al-Tahakkum (arbitrasi), atau kesepakatan bersama suatu kelompok 
masyarakat, ia tidak selalu bersifat logis, bila komunitas masyarakat sepakat maka jadilah ia bahasa.

Ibrahim Musthafa dan Ibrahim Anis merupakan ahli Bahasa kotemporer, keduanya sering disejajarkan dengan tokoh-tokoh pembaharu kajian Nahwu kotemporer lainnya, seperti Syauqi Dhaif dan lainnya. Ibrahim Musthafa dan Ibrahim Anis bukanlah bukanlah perintis awal dalam tajdid (pembaharuan) kajian ilmu Nabwu, dimasa klasik tercatat seorang tokoh kelahiran Kordoba (Spanyol) bernama Ibnu Madha' al-Qurthubi yang pemikiran-pemikirannya dikategorikan upaya baru dalam kajian ilmu Nahwu. Pemikiran Ibnu Madha' lebih banyak berfokus pada kritik terhadap teori 'amil yang telah mapan dianut para ahli bahasa tradisional. Berangkat dari realita ini, upaya pembaharuan yang dilakukan Ibrahim Musthafa dan Ibrahim Anis adalah tidak lanjut dari upaya yang ada sebelumnya, perbedaanya adalah bahwa Ia tidak berhenti pada kritik terhadap pendekatan analisis kebahasaan yang bersifat logis dan filosofis, lebih jauh ia melakukan upaya untuk menemukan metode-metode baru dalam pengajaran ilmu Nahwu.

Ibrahim Musthafa menuangkan pemikiran-pemikirannya dalam kajian ilmu Nahwu dalam bukunya yang fenomenal berjudul: Ibya' al-Nabwi sementara Ibrahim Anis menulis sebuah karya yang berjudul Asrar al-Lughah. Kedua karya ini cukup mendapat sambutan hangat dikalangan tokoh Pembaharu bahasa kotemporer sekaligus mendapatkan banyak kritikan, seorang tokoh sastra kotemporer sezaman Ibrahim Musthafa, Thaha Husain menyanjung karyanya ini dan memujinya dalam pengantar buku dengan menyebut Ibya' al-Nahwi sebagai terobosan baru di abad ini. Sambutan hangat terhadap pemikiran Ibrahim Musthafa bukan juga berarti bahwa sepenuhnya pemikiran-pemikirannya sepi dari kritikan.

Artikel ini mencoba mengankat isu konsep i'rab dalam pemikiran Ibrahim Musthafa dan Ibrahim Anis. Terdapat beberapa peneliti yang telah mengkaji konsep i'rab dalam pemikiran Ibrahim Musthafa dan Ibrahim Anis, tapi penelitian ini di maksudkan untuk melihat perbandingan konsep i'rab di antara dua tokoh ini. Penelitian ini adalah penelitian deskriptif analisis yang bertujuan: mengkaji pemikiran Ibrahim Musthafa dan Ibrahim Anis mengenai konsep i'rab serta membandingkan kedua konsep tersebut.

\section{Hasil Dan Pembahasan}

\section{A. Konsep I'rab Menurut Ibrahim Musthafa}

Ibrahim Musthafa merupakan salah seorang anggota lembaga (majma') bahasa Arab di kota Kairo. Ia tercatat sebagai tokoh yang secara intens dan serius mempelajari ilmu Nahwu dan ushul-nya, serta melakukan analisa-analisa dan kritik terhadap pemikiran-pemikiran Nabwu Klasik. Upaya kerasnya ini ia tuangkan dalam bukunya yang fenomenal Ibya' al-Nabwi, karyanya ini merupakan 
pemikirannya yang orisinal dalam pembaharuan kajian sintaksis Arab. dalam karyanya ini Ibrahim Musthafa mencoba menawarkan beberapa konsep baru dalam bidang kajian ilmu Nahwu, dan konsep yang ia tawarkan adalah bentuk upaya menyederhanakan dan mempermuadah mempelajari ilmu Nahwu.

Seperti disinggung sebelumnya, kajian ilmu Nahwu sangat dipengaruhi logika dan filsafat dalam merumuskan kaidah-kaidah kebahasaan. Ibrahim Musthafa melihat bahwa dua pendekatan ini tidaklah selalu cocok untuk menganalisis fenomena-fenomena kebahasaan, bahkan Ia merasa bahwa kedua pendekatan ini memunculkan persoalan berupa kerumitan-kerumitan yang seyogyanya tidak perlu ada. Dalam pendahuluan karyanya Ibya' al-Nabwi Ia menuliskan: "Aku sangat berkeinginan membuat perubahan Manbaj (metode dalam) kajian ilmu Nahwu, serta menemukan metode yang mudab untuk mempelajari dan memahami tata bahasa dan Uslub (gaya) bahasa Arab". ${ }^{14}$

Dalam karyanya ini Ibrahim Musthfa mengawali tulisannya dengan kritikan terhadap defenisi ilmu Nahwu. Para Nabwiyin Klasik mendefenisikan Nahwu sebagai :

$$
\text { علم بأصول يعرف بها أحوال أواخر الكلم إعرابا وبناء }
$$
atau bina").

Disiplin ilmu yang menkaji bentuk akbir kata baik dalam bentuk i'rab

Beliau melihat bahwa defenisi ini hanya menitikberatkan aspek lafal (syakli) serta mengabaikan aspek makna bahasa itu sendiri. Ibrahim Mustafa berpandangan bahwa seharusnya bahasa harus dilihat dari dua aspeknya yaitu aspek lafdri dan ma'nawi, kajian ilmu Nabwu yang hanya menitikberatkan pada aspek pertama dipandang sebagai bentuk kepincangan dalam melihat Nahwu secara utuh.

Membatasi ilmu Nahwu hanya pada segi i'rab dalam pandangan Ibrahim Musthafa adalah bentuk penyempitan terhadap ilmu Nahwu itu sendiri. Defenisi seperti itu baginya hanya menyentuh sedikit bidang kajian Nabwu. Defenisi Nahwu seharusnya seperti yang beliau tuliskan dalam karyanya tersebut, yaitu:

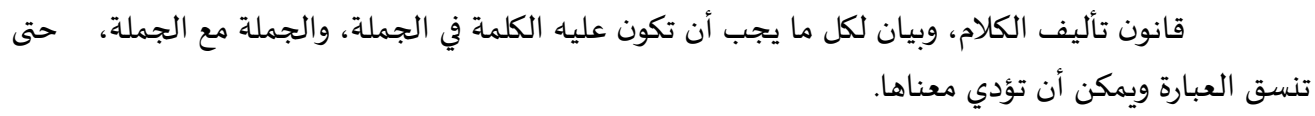

Nabwu adalah disiplin ilmu tentang kaidah menyusun kalimat bahasa Arab, serta ketentuan-ketentuan yang harus dipenubi dalam menyusun kalimat tersebut, sehingga terciptalah ungkapan yang mampu menginformasikan makna secara benar.

${ }^{14}$ Musthafa, Ibrahim, Ibya' al-Nahwi, hlm. 1 
Defenisi ini meniscayakan tiga hal yang harus ada dalam defenisi Nabwu yaitu: ilmu Nabwu adalah disiplin ilmu tentang kaidah menyusun kalimat dalam bahasa Arab, adanya penjelasan-penjelasan tentang ketentuan yang harus di penuhi dalam penyusunan kalimat, dan ketentuan hubungan antar kalimat. ${ }^{15}$

Pembatasan ilmu Nahwu hanya pada aspek i'rab mengabaikan perhatian terhadap banyak hal terkait bahasa Arab, secara khusus hal-hal yang berkaitan dengan penyusunan kalimat. Dalam bahasa Arab terdapat berbagai jenis uslub (gaya) bahasa yang digunakan dalam komunikasi, di antaranya uslub isbat (pola kalimat positif), nafji ( kalimat negatif), taukid (penegasan), taqdim dan ta'kbir dan lain-lain. Ibrahim Musthafa tidak menafikan sepenuhnya bahwa para Nabwiyizin Klasik juga mengulas berbagai gaya bahasa yang tersebut di atas, tapi ia melihat bahwa porsi yang mereka berikan untuk itu tidaklah cukup memadai. Keterpesonaan mereka terhadap persoalan i'rab berdampak pada penitikberatan kajian Nahwu hanya pada pembahasan tentang perubahan akhir kata serta latar belakang perubahan tersebut. ${ }^{16}$

Sejarah mencatat cikal bakal Ilmu Nabwu muncul ketika terjadi kerancuan berbahasa ( $l a b n)$ dikalangan orang-orang non Arab, kerancuan itu terutama dalam mengfungsikan tanda irrab. Lalu muncullah berbagai upaya untuk menyelesaikan persoalan ini, para ahli bahasa yang telah terpengaruh dengan ilmu logika dan filsafat melihat bahwa perubahan i'rab dalam bahasa Arab tidak muncul begitu saja tanpa ada aktor yang menjadi penyebab atas perubahan itu. Belakangan mereka menyebut aktor itu dengan istilah 'amil, teori 'amil jelas satu teori yang di adopsi dari kalangan ahli filsafat. Para ahli filsafat berpandangan bahwa segala sesuatu itu terjadi karena ada (maijud/ma'mul) yang menjadikan (mujid/'ami), atau dengan pernyataan lain bila ada sebab maka ada musabab. Persoalan i'rab ketika di analisa dari sudut pandang teori 'amil memunculkan motivasi besar bagi kalangan ahli bahasa untuk mengungkap 'amil-'amil yang menjadi aktor perubahan itu. Berbagai upaya ini tidak sepi dari perdebatan-perdebatan dan perbedaan pendapat dalam menentukan 'amil yang menjadi penyebab perubahan i'rab tersebut. Pada mulanya mereka menyebut disiplin ilmu yang mereka geluti itu dengan istilah 'Ilal al-I'rab atau Ilal al-Nabwu, dan belakangan mereka menyingkatnya dengan ilmu Nabwu atau I'rab.

Pengaruh filsafat dan logika telihat pada banyak aspek dalam merumuskan konsep 'amil dan seluk beluknya, di antara rumusan-rumusan itu adalah: 1). Setiap perubahan tanda i'rab tidak terlepas dari 'amil yang menjadi aktornya, 'amil itu bisa berbentuk lafdzi (konkrit) atau taqdiri (abstrak); 2). Dua 'amil tidak beramal untuk satu ma'mul; 3). Secara prinsip yang beramal itu hanya fi'il; 4). Isim bisa menjadi 'amil bila memiliki keseupaan dengan fïll dan masih

\footnotetext{
${ }^{15}$ Ibid, hlm. 1-2

${ }^{16} \mathrm{Ibid}, \mathrm{hlm} .3$
} 
banyak lagi contoh pengaruh filsafat dalam merumuskan kaidah Nabwu.$^{17}$ Pada poin pertama terlihat jelas pengaruh filsafat, yaitu pandangan mereka bahwa setiap peristiwa yang terjadi meniscayakan adanya aktor yang menjadikannya, perubahan i'rab tidak mungkin terjadi kecuali karena ada 'amil yang mengaktorinya. Adapun pengaruh filsafat dalam rumusan poin kedua yaitu pandangan para ahli filsafat yang menolak adanya dua aktor dalam satu peristiwa, sebab ini berimplikasi mengadakan sesuatu yang sudah ada (tabshi alhashil) dan itu perkara yang mustahil. Dari beberapa contoh di atas terlihat jelas bagaimana pengaruh filsafat mempengaruhi pemikiran Nabwiyiin dalam menganalisa persoalan kebahasaan.

Dalam karyanya Ibya' al-Nabwi, terlihat bahwa Ibrahim Musthafa menginginkan perubahan manhaj dalam mengkaji ilmu Nabwu. Ibarahim Musthafa mengelompokkan qawaid nahwu menjadi dua kelompok; kelompok pertama berkaitan dengan qawaid-qawaid yang tidak terlalu sulit dalam mempelajarinya, seperti pembahasan 'adad (bilangan) dan hukumnya. Ia melihat para ulama tidak banyak berbeda pandangan mengenai persoalan ini. Kelompok kedua adalah qawaid yang berkaitan dengan tarkib (struktur) dan fungsi i'rab seperti isim yang di-rafa'-kan atau di-nashab-kan. Qawaid dalam kelompok ini menjadi ranah khilaf di antara para ahli Nahwu terkait latar belakang perubahan i'rab atau 'amil yang menjadi aktor perubahan 'amil. Menyikapi qawaid kelompok kedua ini Ibrahim Musthafa berkeberatan dengan pendekatan.

Ibrahim Musthafa sejatinya tidaklah menolak konsep i'rab seperti yang dikemukakan para Ulama Nabwu Tradisional, hanya saja Ia menginginkan satu pendekatan yang berbeda dalam memperlakukan irab. Menurut pandangannya semestinya harus terintegrasi dengan struktur atau fungsi kalimat. Dengan pendekatannya ini i'rab bisa dijelaskan secara terang fungsinya dalam kalimat. ${ }^{18}$ Secara garis besar Ia mengelompokkan tanda i'rab dalm dua fungsi: pertama: rafa' berfungsi sebagai penanda subjek (isnad), kedua: jar berfungsi sebagai penanda idhafah (genitif). sementara tanda nashab tidak memiliki fungsi apa-apa, ia hanya dipandang sebagai baris yang pengucapannya ringan setara dengan baris sukun pada dialek 'amiyah.'

Ibrahim Musthafa berpandangann bahwa tanda i'rab hanya dhammah dan kasrah, dan kedua tanda ini bukanlah disebabkan oleh amil akan tetapi mutakallim atau penuturlah yang memunculkan perubahan tanda i'rab ini untuk fungsi tertentu dalam struktur kalimat. Pandangan ini merupakan pokok utama pemikirannya dalam bukunya Ibya' al-Nabwi. Pemikiran Ibrahim Musthafa ini sejalan dengan ulama Nabwu asal Kordoba Ibnu Madha' al-Qurthubi yang

\footnotetext{
${ }^{17}$ Ibid, hlm. 23-25

${ }^{18} \mathrm{Ibid}, \mathrm{hlm} .3$

${ }^{19}$ Ibid, hlm. 50
} 
menolak teori 'amil yang yang menjadi aktor perubahan i'rab. ${ }^{20}$ Dhammah sebagai tanda i'rab berfungsi sebagai penanda bahwa yang menyandang harkat itu berkedudukan sebagai subjek, dan yang masuk dalam kelompok ini yaitu: fail, naibul fa'il dan mubtada'. Sementara harkat kasrah berfungsi sebagai penanda bahwa kata yang menyandang harkat itu berkedudukan sebagai idhafah (genitif), dan Ia mengelompokkan idhafah dalam dua kategori: idhafah yang tidak didahului huruf jar dan idhafah yang di dahului huruf jar.

Adapun harkat fathah, Ibrahim Musthafa secara tegas menolak setatusnya sebagai tanda i'rab. Seperti telah dikemukakan sebelumnya, Ia berpendapat bahwa harkat fathah dimunculkan bukanlah dimaksudkan untuk mewakili fungsi makna tertentu, tapi harkat ini hanya bertujuan sebatas untuk meringankan komunikasi semata. Di samping menolak fathah sebagai tanda i'rab, ibrahim Musthafa juga menolah konsep tanda i'rab cabang (far'iyah). Seperti tanda i'rab waw dan ya' pada jamak muzakar al-salim di saat rafa' dan jar dalam pandangannya kedua tanda i'rab ini sangat dibuat-buat. Semestinya ia dikembalikan statusnya sebagai isim yang mu'rab, adapun tanda i'rab-nya dikembalikan pada status asalnya pada isim mufrad yaitu dhammah di saat rafa' dan kasrah disaat jar. Huruf waw dan ya' yang terdapat pada jama' muzakkar itu bukanlah tanda i'rab, ia hanya berfugsi sebagai isyba' (pemantapan) dalam pengucapan semata. ${ }^{21}$

\section{B. Konsep I'rab Menurut Ibrahim Anis}

Ibrahim Anis merupakan salah seorang Ahli bahasa Arab kotemporer yang memiliki perhatian besar terhadap kajian Ilmu Nahwu, Ia sendiri adalah murid dari Ibrahim Musthafa. Gagasan dan pemikirannya dalam bidang ilmu Nahwu Ia tuangkan dalam bukunya yang terkenal Asrar al-Lughah. Seperti gurunya, Ibrahim Anis merupakan tokoh yang mengupayakan terobosanterobosan baru untuk menemukan solusi agar pengajaran Ilmu Nabwu tidak lagi dirasakan sulit dan rumit di kalangan pelajar. Gagasan dan pemikirannya dalam Ilmu Nahwu ini tidaklah sepi dari berbagai macam kritikan, tapi itu semua tidak mengurangi ketokohan dan sumbangsihnya dalam kajian linguistik Arab.

Dalam bukunya Asrar al-Lughah Ibrahim Anis menegaskan bahwa karyanya itu bukan dimaksudkan merombak ushul (prinsip-prinsip) atau Manhaj (metode) pengkajian Ilmu Nabwu, tapi tulisannya itu dimaksudkan untuk menganalisa secara ilmiyah sejarah i'rab, periode kemunculannya dan prinsipprinsipnya. ${ }^{22}$ Dalam bukunya itu Ia berkata: "kajian ini tidaklah kami maksudkan untuk merubah prinsip-prinsip i'rab, dan tidak pula untuk menemukan formula yang tepat terkait metode pengajarannya ketika mengulas sejarah kemunculan i'rab, tapi kajian ini

20 Thariq Ibrahim al-Ziyadat, Min Mubawalat Taisir al-Nabwi al-Arabi, (Al-Azhar, JuliDesember 2017)

${ }^{21}$ Musthafa, Ibrabim, Ibya' al-Nabwi, hlm. 109

22 Anis, Ibrahim, Asrar al-Lughab (Kairo: Maktabah al-Anjelu al-Misriyah, 1994), cet. 7, hlm. 211 
ditujukan untuk mengkaji secara ilmiyah sejarah munculnya i'rab dan kontribusi kajiannya dikalangan ulama trdisional serta deskripsi i'rab pada masa jabiliyah dan awal Islam di kalangan abli bahasa."

Ibrahim Anis mendasarkan kajiannya pada sumber-sumber sejarah terkait dengan kemunculan i'rab, terutama catatan-catatan sejarah yang berkaitan tentang maraknya praktek kesalahan berbahasa (lahn) dalam membaca al-Quran di kalangan orang-orang non Arab. Ia sendiri banyak meragukan dan terkesan memandang sebelah mata pada riwayat-riwayat yang menceritakan sejarah kemunculan i'rab al-Quran berkaitan dengan labn yang berkembang di kalangan non Arab, dimatanya semuanya itu tak lebih dari kisah-kisah drama yang menghanyutkan. Menurutnya riwayat-riwayat itu tak lain ciptaan para ahli Nabwu, yang dikemas secara cerdas oleh para pujangga tentang fenomena bahasa yang berkembang di tengah-tengah Jazirah Arab. Semua itu mereka lakukan dalam rangka menaikkan pamor bahasa Arab serta membuat sistem tata bahasanya. ${ }^{23}$

Seperti telah menjadi konsensus dikalangan ulama Nahwu bahwa perubahan tanda i'rab yang terdapat dalam bahasa Arab berfungsi untuk membedakan makna dalam kalimat. ${ }^{24}$ Kalaupun terjadi perbedaan pandangan, tidaklah dalam ranah penegasian eksistensi i'rab itu sendiri. Perbedaan yang muncul adalah pada ketidak setujuan sebagian ulama Nahwu tentang peranan 'amil dalam menentukan perubahan tanda i'rab, seperti pandangan yang dianut oleh ulama Nahwu dari Andalusia Ibnu Madha' al-Qurtubi. Tapi sejarah mencatat bahwa terdapat seorang tokoh Nahwu bernama Abu Ali Muhammad bin al-Mustanir yang populer dengan panggilan Qutrub (w. $206 \mathrm{H}$ ) yang menafikan peranan i'rab dalam menentukan makna. ${ }^{25}$ Tentu pandangan ini banyak mendapatkan tantangan, seorang ulama Nahwu lain Abu al-Qasim alZajaji dalam karyanya al-Idhah Fi Tlal al-I'rab menguraikan: bahwa ketika sebuah kata (isim) teletak dalam sebuah kalimat, sangat sulit untuk menentukan fungsinya bila tanda i'rab-nya seragam dengan isim yang lain yang sama-sama terdapat dalam kalimat. Dalam kasus ini Ia membuat contoh kalimat ضرب زيد عمرا زي tanda Rafa' pada kata زيد berfungsi sebagai penanda bahwa kata tersebut subjek (pelaku), dan tanda nasab berfungsi penanda bahwa kata tersebut berfungsi sebagai objek (penderita). ${ }^{26}$

Dalam karyanya yang lain al-Zajaji menyebutkan bahwa pada prinsipnya, i'rab itu berlaku pada isim, sedangkan fi'il dan buruf itu hukumnya mabni. Tanda i'rab yang terdapat pada isim berfungsi untuk membedakan kata yang berfungsi

\footnotetext{
${ }^{23}$ Ibid, hlm. 198

${ }^{24}$ Abdu al-Tawwab, Ramadhan, Fushul fi Fiqhi al-Arabiyah (Kairo: Maktabah al-Khanji, 1999), hlm. 371

${ }^{25} \mathrm{Ibid}$, hlm. 372

${ }^{26}$ Al-Zajjaji, Al-Idhah fi Tlal al-Nahwi (Beirut: Dar al-Nafais, 1979), hlm. 91
} 
sebagai fail (subjek) dengan kata yang berfungsi sebagai maf'ul (objek) atau sebagai pembeda antara mudhaf dan mudhaf ilaih. Fungsi-fungsi itu hanya berlaku pada isim bukan pada fïil atau buruf. ${ }^{27}$

Senada dengan pandangan al-Zajaji, Ibnu Faris dalam kitabnya al-Shabibi Fi Figh al-Lughah menjelaskan bahwa i'rab berfungsi sebagai pembeda makna, sekaligus berfungsi sebagai petunjuk tujuan pembicaraan mutakallim. ${ }^{28}$ Dalam sebuah contoh kalimat, bila seseorang mengatakan: ما أجمل زهر tanpa membuat tanda írab pada kata زهر dan أجمل, maka sulit untuk menentukan maksud dari

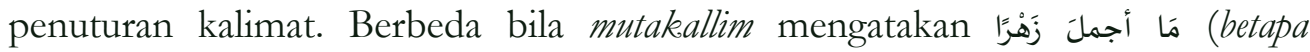
indahnya bunga itu), kalimat ini bermakna ta'ajjub (kagum), atau mutakallim menyebutkan مَا أجمَل زهرٌ (bunga itu tidak indah) jelas kalimat ini adalah kalimat negatif, atau bila mutakalim mengatkan ما أجملُ زهرٍ (apa yang indah dari bunga?) kalimat ini adalah kalimat istifham (pertanyaan). Dari tiga contoh kalimat di atas terlihat jelas fungsi i'rab dalam menentukan makna kalimat.

Dalam sejarah perkembangan ilmu Nabwu, Qutrub adalah tokoh yang pandangannya berbeda sama sekali dengan pendapat yang lazim dianut para ulama Nabwu. Seperti di singgung di atas bahwa para ulama Nahwu secara mayoritas berpandangan bahwa i'rab dalam bahasa Arab itu berfungsi sebagai penanda makna, berbalik dengan pandangan umum itu Qutrub berpandangan bahwa tanda-tanda i'rab tidak ada kaitannya dengan makna. Tanda-tanda itu dalam pandangannya dibuat agar komunikasi berjalan cepat, dan juga dalam rangka menghindari pertemuan dua huruf yang mati ketika washal (bersambung). Mengenai persoalan ini Ia berkata: "Sesungguhnya orang Arab membuat tanda i'rab dalam bahasa mereka, sebab isim di saat waqf (berhenti) mesti berbaris sukun. Lalu mereka membuat harakat (baris) ketika washal (bacaan bersambung) agar tidak terjadi kesulitan dalam komunikasi, lalu dipilihlah beberapa harakat (baris) yang cocok untuk mempermudah terlaksananya komunikasi. ${ }^{29,}$

Dalam catatan sejarah pendapat Qutrub mengenai konsep i'rab dianggap keluar dari prndapat umum yang dianut para ulama Nabwu atau dalam bahasa lain Ia dianggap keluar dari konsensus ulama Nabwu yang sudah mapan. Pendapat yang tidak umum ini belakangan diamini pakar bahasa Arab kotemporer Ibrahim Anis. Dalam sejarah kajian ilmu Nabwu ketentuanketentuan me-rafa'-kan fail, me-nashab-kan maf'ul atau men-jar-kan mudhaf ilaih merupakan kaidah-kaidah yang telah disepakati serta tidak diragukan para ulama. Para ulama ini berkomentar bahwa sekiranya Qutrub konsisten dengan pandangannya, tentu Ia akan me-rofa'-kan maful atau me-nasab-kan fail dalam

\footnotetext{
${ }^{27}$ Al-Zajjaji, Al-Jumal, hlm. 260

${ }^{28}$ Ibnu Faris, al-Shabibi Fi Figh al-Lughah (Bairut: Dar al-Kutub al-Ilmiyah, 1998), cet. 1, hlm. 190

${ }^{29}$ Ramadhan Abdu al-Tawwab, op.cit., hlm. 372
} 
sebuah kalimat, sebab mengacu pendapatnya bahwa baris hanya menggantikan sukun agar komunikasi jadi seimbang. Karena itu baris apa pun yang dipilih tidak menjadi persoalan, tentu yang terjadi adalah penyimpangan-penyimpangan dari kaidah yang berlaku dalam bahasa Arab.

Ibrahim Anis dalam paparannya tentang i'rab berpandangan, bahwa kajian i'rab muncul didasarkan atas dominasi para ahli Nahwu terhadap para penyair dan sastrawan. Dampaknya adalah dominasi pemikiran mereka dalam tata bahasa Arab. Tidak banyak ulama seperti Ibnu Madha' atau Ibrahim Musthafa yang melakukan kritik terhadap pemikiran Nahwu yang dianggap sudah mapan dan tidak perlu diganggu gugat lagi. Dalam kajiannya tentang i'rab bisa dilihat konsep i'rab dalam pandangan Ibrahim Anis: ${ }^{30}$

Pertama: perubahan tanda i'rab tidak memiliki fungsi apa-apa dalam menentukan sebuah makna kata. Harkat i'rab seperti dhammah, fathah atau kasrah tidaklah berperan menentukan bahwa kata yang menyandangnya berkedudukan sebagai fail, maful atau mudhaf ilaih. Dalam pandangannya tanda-tanda i'rab itu tidak lain fungsinya untuk menghubungkan kata dengan kata lainnya, dengan pengertian lain tanda itu dibutuhkan untuk menghindari pertemuan dua huruf sukun ketika washal (bersambung). Pemahaman ini meniscayakan bahwa struktur kalimatlah yang menentukan jabatan kata dalam kalimat apakah berkedudukan sebagai fail, maful atau idhafah.

Kedua: menurut Ibrahim Anis terdapat dua faktor yang berkontribusi terhindarnya dari pertemuan dua huruf sakin. Faktor pertama yaitu di utamakannya huruf atas baris tertentu, seperti diprioritaskannya huruf halaq dari baris fathah. Faktor kedua yaitu kecendrungan untuk menyamakan harkat yang berdekatan, atau yang dinamakan dengan harmoni vokal. Berbeda dengan pandangan para ulama Nabwu Klasik yang ketika mendengar harkat-harkat i'rab lalu menafsirkan bahwa tanda-tanda itu berfungsi sebagai subjek, objek dan lainnya. Dalam pandangan Ibrahim Anis penafsiran ini tidak lah tepat, sebab menurutnya tanda-tanda i'rab yang ada dalam bahasa Arab itu tidaklah dimaksudkan untuk fungsi-fungsi tertentu, harkat yang terdengar itu hanyalah harkat biasa yang fungsinya tidak lebih untuk menyambung kata.

Ketiga: para ahli Nahwu Klasik meyakini fungsi harkat-harkat i'rab sebagai penanda sebuah makna, atas dasar inilah menjadi sebuah kemestian dalam bahasa Arab untuk memberikan harkat atau tanda i'rab sesuai kaidah-kaidah yang sudah mereka tetapkan. Ketika membuat kalimat الرجلُ قائم maka mereka memberikan baris dhammah pada kata rajul, padahal menurut Ibrahim Anis cukup men-sakin-kan huruf lam pada kata الرجل, dengan alasan tidak ditemukan alasan yang bersifat mendesak untuk meletakkan tanda baris. Pada kasus kata yang tanda i'rab-nya huruf, menurut Ibrahim Anis tanda itu adalah satu

${ }^{30}$ Anis, Ibrahim, Asrar al-Lughah, ((Kairo: Maktabah al-Angelo, 1994), hlm. 211 
kekhususan yang terdapat pada kabilah tertentu, sementara kabilah yang lain memiliki kekhususan yang lain. Sayangnya para ulama Nahwu memukul rata kekhususan itu dan membuat kaidah-kaidah yang diterapkan secara sama dalam bahasa Arab. Dalam satu kasus misalnya ada kabilah Arab yang ketika mengucapkan mutsanna dengan ya' dalam semua kondisi, lalu pada kabilah lain mereka mengucapkannya dalam bentuk alif dalam semua kondisi. Para ulama yang tidak memahami rahasia ini melakukan penggabungan dua tanda ini dengan menkhususkan ya' sebagai tanda nashab dan jar, sementara huruf alif sebagai tanda rafa'.

\section{Penutup}

Dalam sejarah perkembangan ilmu Nahwu, konsep i'rab sebagai ciri khas yang dimiliki bahasa Arab telah diterima secara umum oleh para ulama. Para ulama Nahwu secara umum meyakini bahwa perubahan tanda i'rab itu disebabkan oleh aktor-aktor tertentu yang mereka istilahkan dengan 'amil, perubahan i'rab yang terjadi dalam bahasa Arab itu memiliki fungsi dalam menentukan jabatan dan makna kata. Belakangan muncul beberapa tokoh yang menggugat kebenaran beberapa konsep terkait dengan i'rab, dimasa klasik ada dua tokoh yang mengkritik tajam beberapa bagian dari konsep i'rab yaitu: Abu Ali Muhammad bin al-Mustanir yang populer dengan panggilan Qutrub dan Ibnu Madha' al-Qurtubi. Dalam catatan sejarah Qutrub menolak sama sekali konsep i'rab yang dianut mayoritas ulama Nahwu, sementara Ibnu Madha' hanya menolak konsep amil yang dianggap berperan dalam menentukan perubahan tanda i'rab. Pemikiran kedua tokoh ini dimasa kotemporer kembali diadopsi beberapa ulama, terutama ulama pembaharu yang menginginkan pendekatan baru dalam pengkajian ilmu Nabwu agar pembelajarannya lebih praktis dan mudah. Di antara ulama yang mengadopsi pemikiran kedua tokoh ini adalah Ibrahim Musthafa dan Ibrahim Anis.

Bila diamati secara seksama pemikiran Ibrahim Musthafa memiliki kemiripan dengan pemikiran Ibnu Madha'. Keserupaan itu terlihat pada pengabaian keduanya pada konsep 'amil yang dikembangkan dan dianut para Ulama Klasik. Ibrahim Musthafa dalam bukunya Ihya' al-Nabw menolak konsep 'amil ini dan menganggapnya sebagai biang utama kerumitan-kerumitan pengajaran Ilmu Nabwu. Dalam mengkaji tanda i'rab Ibrahim Mustafa hanya menerima dhammah dan kasrah sebagai tanda i'rab, dhammah berfungsi sebagai penanda subjek seperti fail, naib al-fail dan mubtada'. Sedangkan kasrah berfungsi sebagai penanda bahwa kata yang menyandangnya adalah idhafah (genitif). Adapun fathah dalam pandangannya bukanlah tanda i'rab dan tidak memiliki fungsi apa-apa dalam menentukan sebuah makna, harkat ini dipilih karena dianggap harkat yang ringan diucapkan seperti sukun yang dianggap ringan dan dipilih ketika waqaf (berhenti). Ibrahim Musthafa juga menolak konsep i'rab far'iyah (cabang) seperti tanda i'rab waw dan ya' pada jama' muzakekar, menurutnya 
tanda i'rab-nya harus dikembalikan pada bentuknya semula ketika berbentuk isim mufrad. Dalam pandangan Ibrahim Mustafa, yang benar bahwa waw dan nun atau ya dan nun hanya berfungsi sebagai isyba' (pemantapan) bukan sebagai tanda i'rab, tanda i'rab-nya adalah dhammah ketika rafa' dan kasrah ketika jar.

Adapun pemikiran Ibrahim Anis sangat bersesuaian dengan pemikiran ulama Nabwu klasik Qutrub, dimana keduanya menolak konsep i’rab yang dianut mayoritas ulama Nahwu. Ketika mayoritas ulama Nahwu berkeyakinan bahwa perubahan tanda i'rab yang terdapat dalam bahasa Arab berfungsi untuk menentukan makna dan jabatan sebuah kata, disaat bersamaan Ibrahim Anis menganggap para ulama Nahwu telah melakukan kekeliruan dalam menafsirkan perubahan i'rab yang terjadi dalam komunikasi orang-orang Arab. Dalam pandangan Ibrahim Anis perubahan i'rab dalam bahasa Arab tidak memiliki fungsi apapun dalam menentukan makna kata, yang jadi penentu adalah posisi kata itu dalam struktur kalimat. Adapun harkat dhammah, fathah atau kasrah dimunculkan hanya bertujuan untuk menghindari pertemuan dua huruf yang mati sehingga pengucapannya lebih mudah.

\section{Bibliografi}

Abdullah bin Ahmad al-Fakihi, Syarah al-Fawakih al-Janiyah 'ala Mutammimah alJurumiyah, Bandung: Syirkah al-Ma'arif

al-Masluth, Abd al-Hamid, Al-Adab Al-Arabi Baina Al-Jabiliyyah wa AlIslam,Mesir: Al-Mathba'ah al-Muniriyah, 1995

al-Zajjaji, Al-Idhah fi Tlal al-Nahwi, Beirut: Dar al-Nafais, 1979

Anis, Ibrahim, Asrar al-Lughah, Kairo: Maktabah al-Anjelu al-Misriyah, 1994

Abdu al-Tawwab, Ramadhan, Fushul fi Fiqhi al-Arabiyah, Kairo: Maktabah alKhanji, 1999

Asrina, Khilafiyah Nahwiyah: Dialektika Pemikiran Nahwu Basrah dan Kufah dalam Catatan Ibn al-Anbari, MIQOT, vol. XL no. 2 (2016)

D. Hidayat, Al-Balaghah li Al-Jami' wa al-Syawahid min Kalam al-Badi', Jakarta: PT. Karya Toha Putra

Dhoif , Syauqy, al-Madaris al-Nahwiyah, Mesir: Daar al-Ma'arif, 1976

Ibnu Faris, al-Shahibi Fi Figh al-Lughah, Bairut: Dar al-Kutub al-Ilmiyah, 1998

Musthafa, Ibrahim, Ibya' al-Nahwi, Kairo, 1992

Pransiska, Toni, Konsep I'rab Dalam Ilmu Nabwu (Sebuah Kajian Epistemologis), alMahāra, Vol. 1, No.1 (2015)

Tamam Hasan, al-Ushul, Maroko: Dar al-Tsaqofah, 1991 
178 | Arabiyatuna : Jurnal Bahasa Arab, Vol. 3, No. 1, 2019

Thanthawi, Muhammad, Nasyatu al-Nabwi wa Tarikbu Asyburi al-Nubat, Kairo: Dar al-Ma'arif

Thariq Ibrahim al-Ziyadat, Min Mubawalat Taisir al-Nahwi al-Arabi, Al-Azhar, Juli-Desember(2017)

Wahbah, Majdi dan Kamil Al-Muhandis. Mujam al-Musthalahat al-Arabiyah fi alLughah wa al-Adab, Beirut: Maktabah Lubnan, 1984 